\title{
Perfil clínico e imunológico de bovinos experimentalmente inoculados com veneno bruto e iodado de Bothrops alternatus
}

\author{
[Clinical and immunological characteristics in cattle experimentally inoculated with crude and \\ iodinated Bothrops alternatus venom] \\ N.J.F. Oliveira ${ }^{1}$, M.M. Melo ${ }^{1 *}$, E.R. Lara ${ }^{1}$, M. Lúcia ${ }^{2}$, Z.I.P. Lobato ${ }^{1}$ \\ ${ }^{1}$ Escola de Veterinária - UFMG \\ Caixa Postal 567 \\ 30123-970 - Belo Horizonte, MG \\ ${ }^{2}$ Departamento de Biologia - UNIFENAS - Alfenas, MG
}

\begin{abstract}
RESUMO
Dez novilhas mestiças, distribuídas em dois grupos experimentais $(\mathrm{n}=5)$ receberam na altura média da face cranial do membro anterior direito, entre as articulações umerorradioulnar e do carpo, por via intramuscular superficial, $0,15 \mathrm{mg} / \mathrm{kg}$ de veneno de Bothrops alternatus bruto ou iodado. Todos os animais foram avaliados clinicamente antes - tempo zero - e às $6 \mathrm{e} 10 \mathrm{~h}$, no $2^{\circ}, 3^{\circ}, 4^{\circ}, 5^{\circ}, 8^{\circ}, 11^{\circ}, 18^{\circ}$ e $25^{\circ}$ dias após a inoculação dos venenos. Dois animais do grupo que recebeu veneno bruto foram a óbito às $53 \mathrm{~h} \mathrm{e} 78 \mathrm{~h}$ e os sobreviventes apresentaram apatia, letargia, anorexia, postura indicativa de dor, melena, petéquias e sufusões nas mucosas, aumento do tempo de preenchimento capilar, enfartamento ganglionar regional, aumento das freqüências respiratória e cardíaca, redução da freqüência de pulsação arterial periférica, elevação da temperatura retal e diminuição da movimentação ruminal. No local da inoculação do veneno bruto houve sangramento e ulceração dérmica, além de aumento significativo na circunferência e dobra da pele do membro inoculado, revelando formação de edema. Todos os animais também foram avaliados imunologicamente no $17^{\circ}, 24^{\circ}, 31^{\circ}, 45^{\circ}, 60^{\circ}$ e $180^{\circ}$ dia. Somente os que receberam veneno bruto produziram anticorpos, detectados até o $45^{\circ}$ dia. Os que receberam veneno botrópico iodado apresentaram alterações gerais e locais de menor intensidade, porém sem produção de IgG nos tempos pesquisados, demonstrando que a iodação alterou a composição bioquímica do veneno, diminuindo sua toxicidade e imunogenicidade.
\end{abstract}

Palavras-chave: bovino, Bothrops alternatus, parâmetros clínicos, iodação, IgG

\begin{abstract}
The effects of bothropic envenomation in 10 crossbred heifers, randomly divided into two groups, that received $0.15 \mathrm{mg} / \mathrm{kg}$ of body weight of Bothrops alternatus crude or iodinated venom were studied. Behavior; attitude; appetite; defecation; urination; mucous membranes; capillary perfusion time; lymph nodes; respiratory, cardiac and pulse frequencies; rectal temperature and rumination frequency diameter and skin fold of the foreleg on the inoculation site were observed before(zero time) and at 6 and $10 \mathrm{~h}$ and on the $2^{\text {nd }}, 3^{\text {rd }}, 4^{\text {th }}, 5^{\text {th }}, 8^{\text {th }}, 11^{\text {th }}, 18^{\text {th }}$ and $25^{\text {th }}$ day after venom inoculation. Two cattle of Bothrops crude venom group, died at 53 and $78 \mathrm{~h}$ and the surviving animals showed apathy, lethargy, anorexia, pain indicative attitudes, melena, hemorrhagic spots and suffusions on mucous membranes, increased capillary perfusion time, enlarged regional lymph nodes, increased respiratory and cardiac frequencies, decreased peripheric arterial pulse frequency, elevated rectal temperature and decreased of ruminal movements. Bleeding, necrotic point and increase $(P \leq 0.05)$ diameter and skin fold of the foreleg were identified on the inoculated site, confirming local edema. All the animals were evaluated for Bothrops alternatus venom specific $\operatorname{Ig} G$ on the $17^{\text {th }}, 24^{\text {th }}, 31^{\text {st }}, 45^{\text {th }}, 60^{\text {th }}$ and $180^{\text {th }}$ day. Only the animals receiving
\end{abstract}

Recebido em 8 de agosto de 2006

Aceito em 13 de abril de 2007

*Autor para correspondência (corresponding author)

E-mail: marilia@vet.ufmg.br

Apoio: $\mathrm{CNPq}$ 
crude venom produced IgG specific until the $45^{\text {th }}$ day. The animals inoculated with iodinated venom showed general alterations and minor local effects and did not produce specific $\operatorname{Ig} G$, indicating that the iodination decreased both toxicity and immunogenicity response.

Keywords: cattle, Bothrops alternatus, signs pathology, iodination, $\operatorname{Ig} G$

\section{INTRODUÇÃO}

Apesar dos numerosos trabalhos sobre frações isoladas dos venenos de serpentes, pesquisas sobre a clínica dos envenenamentos ofídicos na veterinária são escassas, particularmente nos bovinos. Araújo e Belluomini (1960-62), ao estudarem o efeito do veneno botrópico em bovinos, utilizaram somente um único animal inoculado com veneno de Bothrops alternatus e Soerensen et al. (1995) pesquisaram o envenenamento em um número reduzido de animais sem avaliação estatística. Menezes (1995) relatou casos clínicos de acidente botrópico. Não realizou, porém, diagnóstico imunológico confirmando a presença de veneno no sangue circulante dos animais $\mathrm{e}$ conseqüentemente, desconhecendo a espécie de serpente e a quantidade de veneno que fora inoculada. Portanto, existe uma carência de estudos clínicos sobre o envenenamento botrópico em bovinos, especialmente com a espécie $B$. alternatus, serpente comum e uma das mais letais no Estado de Minas Gerais (Bauab et al., 1994).

Como muitos venenos são fracos imunógenos isto dificulta a confecção de uma vacina. Por isso, diminuir ou mesmo suprimir a letalidade destes compostos sem alterar suas características imunogênicas, seria desejável. A iodação é um dos métodos de detoxificação dos venenos ofídicos, vislumbrado como alternativa para reduzir os efeitos deletérios e manter a antigenicidade das toxinas essenciais para preservar a higidez dos animais a serem hiperimunizados e obter a resposta imunológica (Heneine e Heneine, 2001). Entretanto, pesquisas com veneno iodado foram realizadas principalmente em animais de laboratório ou eqüinos utilizados para a produção de antiveneno (Heneine, 1986; Daniel et al., 1987).

Este trabalho teve o objetivo de estudar os aspectos clínicos de bovinos inoculados com veneno bruto $\mathrm{e}$ iodado de $B$. alternatus $\mathrm{e}$ pesquisar o anticorpo $\operatorname{IgG}$ mediante exames imunológicos.

\section{MATERIAL E MÉTODOS}

Dez novilhas mestiças* (1/2 a 3/4 Holandês/Zebu), com média de $233 \mathrm{~kg}$ de peso corporal e 15 meses idade vermifugadas ${ }^{1}$, vacinadas contra febre aftosa ${ }^{2}$, raiva ${ }^{3}$ e clostridioses ${ }^{4}$ e alojadas em um tie stal, foram alimentadas com dieta balanceada composta de quantidades individuais de silagem de milho e ração ${ }^{5}$ e mistura mineral ${ }^{6}$ à vontade.

Considerando a grande sensibilidade dos bovinos ao veneno botrópico, nessa pesquisa utilizou-se um terço da dose mínima mortal (DMM) por quilo de peso corporal pela via intramuscular (Araújo et al., 1963). Portanto, após sete dias de adaptação ao local, os animais foram distribuídos aleatoriamente em dois grupos experimentais $(\mathrm{n}=5)$ e receberam $0,15 \mathrm{mg} / \mathrm{kg}$ de veneno bruto de $B$. alternatus (grupo VB) e $0,15 \mathrm{mg} / \mathrm{kg}$ de veneno iodado de B. alternatus (grupo VI).

$\mathrm{O}$ veneno bruto cristalizado de $B$. alternatus foi diluído em solução salina $0,9 \%^{7}(20 \mathrm{mg} / \mathrm{ml})$. Para a iodação, uma alíquota desse veneno foi ressuspendida em tampão fosfato $(0,1 \mathrm{M}$ e $\mathrm{pH}$ $8,2)$, na mesma concentração anteriormente feita com a solução salina e a esta mistura foram adicionados, progressivamente, $3,5 \mathrm{ml}$ de iodeto de potássio $(0,1 \mathrm{M})$ para se obter o veneno iodado.

Os venenos, bruto e iodado, foram inoculados na altura média da face cranial do membro anterior direito (MAD), entre as articulações umerorradioulnar e do carpo, por via

*Aprovado pelo Comitê de Ética em Experimentação AnimalUFMG - protocolo 011/2004.

${ }^{1}$ Ranger ${ }^{\circledR}$ - Vallée S A - Produtos Veterinários - Montes Claros, Brasil.

${ }^{2}$ Bovicel ${ }^{\circledR}$ - Vallée S A - Produtos Veterinários - Montes Claros, Brasil.

${ }^{3}$ Raivacel® - Vallée S A - Produtos Veterinários - Montes Claros, Brasil.

${ }^{4}$ Polistar ${ }^{\circledR}$ - Vallée S A - Produtos Veterinários - Montes Claros, Brasil.

${ }^{5}$ Ração Novilhas Itambé 16\%PB - Contagem, Brasil.

${ }^{6}$ Fosbovi $20 \circledR$, Tortuga. - São Paulo, Brasil.

${ }^{7}$ Cloreto de sódio a $0,9 \%$ - Hypofarma - Taubaté, Brasil. 
intramuscular superficial por meio de agulha estéril, marcada com barreira mecânica para atingir a mesma profundidade no momento da aplicação (6mm). Os animais foram avaliados clinicamente conforme Dirksen et al. (1993), antes -tempo zero - e às 6 e $10 \mathrm{~h}$, no $2^{\circ}, 3^{\circ}, 4^{\circ}, 5^{\circ}$, $8^{\circ}, 11^{\circ}, 18^{\circ}$ e $25^{\circ}$ dias após inoculação dos venenos.

No sítio de inoculação dos venenos o edema, estimado pela circunferência do MAD, medido com fita métrica na altura do ponto de aplicação e pela espessura da dobra de pele local, obtida com paquímetro metálico, sendo considerada a média de três aferições de cada parâmetro, além da presença de hemorragia ou necrose local.

O Western Bloting foi utilizado para a detecção da imunoglobulina IgG nos animais que receberam os venenos, bruto e iodado no $17^{\circ}$, $24^{\circ}, 31^{\circ}$ e $45^{\circ}$ dia.

A corrida eletroforética (Minigel Protean ${ }^{8}$ ) foi realizada em condições não desnaturantes em gel de separação de poliacrilamida a $12 \%$ e o de empilhamento a $4 \%$. A concentração de veneno utilizada por minigel foi de $20 \mu \mathrm{g}$ em canaleta única.

As proteínas foram transferidas para membrana de nitrocelulose de $0,45 \mu \mathrm{m}$ que foi em seguida bloqueada overnight em temperatura de 2 a $8^{\circ} \mathrm{C}$ com solução salina fosfato $1 \mathrm{M}, \mathrm{pH} 7,4$ acrescida de $5 \%$ de leite em pó desnatado ${ }^{9}$ (solução de bloqueio). Em seguida, a membrana foi lavada três vezes com tampão salina fosfato (PBS) $1 \mathrm{M}$, pH 7,4, alternando com PBS acrescida de Tween 20 a $0,5 \%$ (PBST). Como controle negativo utilizou-se pool das amostras no tempo zero (antes da inoculação do veneno) e como controle positivo, soros dos bovinos que receberam veneno de Bothrops alternatus.

O soro a ser testado foi diluído 50 vezes em solução de bloqueio e incubado sob a membrana em sistema de canaletas multiscreen ${ }^{10}$ que foi agitado manualmente à temperatura ambiente por uma hora, sendo em seguida, a membrana lavada como descrito anteriormente.

\footnotetext{
${ }^{8}$ Bio Rad, Life Science Research, EUA

${ }^{9}$ Molico Nestlé - São Paulo, Brasil

${ }^{10}$ Sigma Aldrich Corporation, EUA.
}

O conjugado anti-IgG bovino-peroxidase foi diluído 4000 vezes em solução de bloqueio e incubado por $1 \mathrm{~h}$ sob agitação à temperatura ambiente. Após a lavagem da membrana a reação foi revelada com o kit comercial de diaminobenzidina $(\mathrm{DAB})^{11}$ durante cinco minutos, sendo a reação interrompida com água de torneira.

Os resultados foram observados visualmente pela presença ou ausência de reação de cor entre as linhas, utilizando-se como referência os controles positivos e negativos.

O experimento, montado em parcelas subdivididas, teve nas parcelas os grupos veneno bruto e veneno iodado - e nas subparcelas, os tempos, no delineamento experimental inteiramente ao acaso. Devido ao óbito de dois animais do grupo que recebeu veneno bruto, para a avaliação dos sobreviventes, três repetições foram consideradas neste grupo e cinco no grupo veneno iodado. Os dados foram submetidos à análises de variância normal e de regressão, utilizando-se os sistemas SAS (User's... 1997) e SAEG (Sistema..., 1998), e as médias foram comparadas utilizando-se o teste SNK, com 5\% de probabilidade de erro.

\section{RESULTADOS E DISCUSSÃO}

$\mathrm{Na}$ Tab.1 mostram-se as alterações clínicas sistêmicas e locais dos animais que receberam veneno bruto e iodado.

A dose total média dos venenos inoculados foi de $34,95 \mathrm{mg}$ e simulou um dos locais de maior incidência de acidentes ofídicos, conforme Biondo et al. (1993) e uma das vias citadas pela WHO (World..., 2001). Essa dose, apesar de ter sido menor que os $100 \mathrm{mg}$ estimados numa inoculação de gravidade moderada nos envenenamentos botrópicos (Ferreira Jr. e Barraviera, 2004) e menor que os $130 \mathrm{mg}$ injetados em $75 \%$ dos acidentes com $B$. alternatus, estimados por Araújo et al. (1963), levou ao óbito dois animais do grupo VB às $53 \mathrm{~h}$ e 78h. Esses animais apresentaram extremidades frias e sangramento no local inoculado, hemorragias em feridas recentes e áreas enegrecidas na pele clara, indicativo de hematoma.

${ }^{11}$ DAB- Vector 4100 
Oliveira et al.

Tabela 1. Valores médios da freqüência respiratória em movimentos respiratórios por minuto, freqüência cardíaca em batimentos por minuto, freqüência de pulsação arterial por minuto, temperatura retal em ${ }^{\circ} \mathrm{C}$, freqüência de movimentos ruminais em 5 minutos, circunferência do membro inoculado em $\mathrm{cm}$ e da dobra de pele no local da inoculação em cm em bovinos antes (T0) e após o envenenamento botrópico experimental com veneno bruto (VB) e iodado (VI) de B. alternatus

\begin{tabular}{|c|c|c|c|c|c|c|c|c|c|c|c|c|c|c|}
\hline \multirow{2}{*}{$\begin{array}{c}\text { Variáveis } \\
\text { Grupos } \\
\text { Tempos }\end{array}$} & \multicolumn{2}{|c|}{$\begin{array}{l}\text { Freqüência } \\
\text { respiratória }\end{array}$} & \multicolumn{2}{|c|}{ Freqüência cardíaca } & \multicolumn{2}{|c|}{$\begin{array}{c}\text { Freqüência de } \\
\text { pulsação arterial }\end{array}$} & \multicolumn{2}{|c|}{$\begin{array}{c}\text { Temperatura } \\
\text { retal }\end{array}$} & \multicolumn{2}{|c|}{$\begin{array}{c}\text { Freqüência de } \\
\text { movimentos ruminais }\end{array}$} & \multicolumn{2}{|c|}{$\begin{array}{l}\text { Circunferência do } \\
\text { membro inoculado }\end{array}$} & \multicolumn{2}{|c|}{$\begin{array}{c}\text { Dobra da } \\
\text { pele }\end{array}$} \\
\hline & VB & VI & VB & VI & VB & VI & VB & VI & VB & VI & VB & VI & VB & VI \\
\hline т0 & $24,00 \mathrm{Ad}$ & $24,80 \mathrm{Aa}$ & $89,00 \mathrm{Abcd}$ & $81,40 \mathrm{Aa}$ & $82,00 \mathrm{Aab}$ & $75,40 \mathrm{Aa}$ & $38,93 \mathrm{Ac}$ & $38,76 \mathrm{Abc}$ & $9,00 \mathrm{Aa}$ & $8,30 \mathrm{Aa}$ & $28,17 \mathrm{Ae}$ & $29,20 \mathrm{Ae}$ & $0,80 \mathrm{Ad}$ & $0,73 \mathrm{Ade}$ \\
\hline $6 \mathrm{~h}$ & 28,00Acd & $25,40 \mathrm{Aa}$ & 102,00Aabcd & $79,60 \mathrm{Ba}$ & $70,00 \mathrm{Ab}$ & $75,00 \mathrm{Aa}$ & 39,50Aab & 39,10Aabc & $7,00 \mathrm{Ba}$ & $12,00 \mathrm{Aa}$ & $36,00 \mathrm{Aa}$ & $31,10 \mathrm{Bd}$ & $4,80 \mathrm{Ab}$ & $1,64 \mathrm{Bd}$ \\
\hline $10 \mathrm{~h}$ & $36,00 \mathrm{Abcd}$ & $24,20 \mathrm{Ba}$ & $121,67 \mathrm{Aa}$ & $85,20 \mathrm{Ba}$ & $71,33 \mathrm{Bb}$ & $85,60 \mathrm{Aa}$ & 39,73Аа & $39,22 \mathrm{Aa}$ & 10,33Aa & $11,20 \mathrm{Aa}$ & $35,33 \mathrm{Aa}$ & $32,80 \mathrm{Bc}$ & $6,00 \mathrm{Ab}$ & $3,88 \mathrm{Bb}$ \\
\hline $2^{\circ}$ dia & 41,67Aabc & $28,00 \mathrm{Ba}$ & $79,33 \mathrm{Ad}$ & $76,20 \mathrm{Aa}$ & $53,33 \mathrm{Bc}$ & 72,40Aa & 39,57Aab & $38,94 \mathrm{Babc}$ & $9,00 \mathrm{Aa}$ & $10,20 \mathrm{Aa}$ & $35,83 \mathrm{Aa}$ & $35,90 \mathrm{Aa}$ & 7,63Aa & $5,54 \mathrm{Ba}$ \\
\hline $3^{\circ}$ dia & $55,00 \mathrm{Aa}$ & $26,60 \mathrm{Ba}$ & 110,00Aab & $76,20 \mathrm{Ba}$ & $50,00 \mathrm{Bc}$ & $70,80 \mathrm{Aa}$ & 39,37Aabc & $38,68 \mathrm{Bc}$ & $8,67 \mathrm{Ba}$ & $11,40 \mathrm{Aa}$ & 34,67Aa & $34,10 \mathrm{Ab}$ & $5,43 \mathrm{Ab}$ & $3,10 \mathrm{Bc}$ \\
\hline $4^{\circ}$ dia & $52,67 \mathrm{Aa}$ & $28,20 \mathrm{Ba}$ & 112,13Aab & $80,00 \mathrm{Ba}$ & 82,33Aab & $75,00 \mathrm{Aa}$ & 39,73Aa & $39,12 \mathrm{Babc}$ & 7,33Aa & $10,00 \mathrm{Aa}$ & $33,00 \mathrm{Ab}$ & $31,30 \mathrm{Bd}$ & $5,13 \mathrm{Ab}$ & $0,87 \mathrm{Be}$ \\
\hline $5^{\circ}$ dia & 44,33Aab & $22,40 \mathrm{Ba}$ & 111,00Aab & $72,40 \mathrm{Ba}$ & 83,33Aab & $75,00 \mathrm{Aa}$ & 39,73Aa & 38,94Babc & $5,66 \mathrm{Ba}$ & 8,80Aa & $32,33 \mathrm{Abc}$ & 30,60Bde & $2,83 \mathrm{Ac}$ & $0,83 \mathrm{Bde}$ \\
\hline $8^{\circ}$ dia & 43,33Aab & $28,40 \mathrm{Ba}$ & 104,67Aabc & $75,60 \mathrm{Ba}$ & $94,00 \mathrm{Aa}$ & $71,20 \mathrm{Ba}$ & $38,90 \mathrm{Ac}$ & $39,26 \mathrm{Aa}$ & $8,66 \mathrm{Aa}$ & $10,60 \mathrm{Aa}$ & $32,00 \mathrm{Abc}$ & 30,00Bde & $1,23 \mathrm{Ad}$ & $0,72 \mathrm{Ade}$ \\
\hline $11^{\circ} \mathrm{dia}$ & 33,33Abcd & $21,40 \mathrm{Ba}$ & 93,00Abcd & $75,8 \mathrm{Ba}$ & 89,67Aab & $68,20 \mathrm{Ba}$ & 39,43Aabc & 39,04Aabc & $8,66 \mathrm{Aa}$ & $9,20 \mathrm{Aa}$ & $30,83 \mathrm{Acd}$ & 30,30Ade & $1,07 \mathrm{Ad}$ & 0,74 Ade \\
\hline $18^{\circ} \mathrm{dia}$ & 32,33Abcd & $29,60 \mathrm{Aa}$ & $88,00 \mathrm{Abcd}$ & $76,6 \mathrm{Aa}$ & $94,00 \mathrm{Aa}$ & $72,40 \mathrm{Ba}$ & 39,13Aab & 39,14Aab & 12,00Aa & $11,20 \mathrm{Aa}$ & 30,90Acd & $29,17 \mathrm{Be}$ & $0,80 \mathrm{Ad}$ & $0,75 \mathrm{Ade}$ \\
\hline $25^{\circ} \mathrm{dia}$ & $23,00 \mathrm{Ad}$ & $28,40 \mathrm{Aa}$ & $81,33 \mathrm{Acd}$ & $81,6 \mathrm{Aa}$ & 78,67Aab & $80,40 \mathrm{Aa}$ & 39,17Aabc & 39,12Aabc & $9,00 \mathrm{Aa}$ & $10,80 \mathrm{Aa}$ & 29,67Ade & 30,70Ade & $0,73 \mathrm{Ad}$ & 0,76 Ade \\
\hline
\end{tabular}

Médias seguidas de letras minúsculas distintas indicam diferenças entres tempos dentro de cada grupo (teste SNK, P $\leq 0,05$ ).

Nos animais do grupo VB, $15 \mathrm{~min}$ após a inoculação foram observados desconforto, ausência ou apoio na pinça do MAD, devido provavelmente à dor local, semelhantemente ao descrito em cães envenenados com venenos botrópicos (Takahira, 1999; Santos et al., 2003; Silva Jr., 2003). Essa postura alterada perdurou até o quinto dia e não foi mais observada após o oitavo dia. A dor no envenenamento botrópico está relacionada ao efeito de aminas biogênicas e mediadores inflamatórios liberados e à compressão de terminais nervosos associada ao edema, alterações provocadas pela ação local do veneno (Picolo et al., 2002).

Nos animais do grupo VI, o desconforto e a ausência ou o apoio na pinça do MAD ocorreu entre 6 e 30h, indicando que a iodação suprimiu grande parte dessa ação local do veneno botrópico. Já em decúbito esternal, todos os bovinos do grupo VB permaneceram com o membro anterior direito estendido até o terceiro dia após a inoculação. Essa postura, também indicativa de dor, denotando a menor flexão das articulações acometidas pelo grande edema, também foi observada em bovinos expostos a venenos botrópicos por Menezes (1995). Somente um animal do grupo VI apresentou essa postura (às 15h). A iodação consiste na incorporação gradual, em pequenas alíquotas, da solução de iodeto de potássio estável às toxinas, para abolir os efeitos letais e patofisiológicos destas, por modificar estruturalmente as proteínas. $\mathrm{Na}$ iodação controlada, grupamentos tirosil e histidil das proteínas são modificados pela troca de íons iodo, modificando o ponto isoelétrico das proteínas. Essa modificação na capacidade ionizante das moléculas iodadas é capaz de impedir a sua ação farmacológica e o efeito deletério é abolido. Porém, nem todas as moléculas de proteína são detoxicadas com a iodação, permanecendo algum efeito residual da toxina (Heneine e Heneine, 2001).

Nos animais do grupo VB foram observados, após $3 \mathrm{~h}$, aparecimento de letargia que perdurou até o terceiro dia e apatia pronunciada entre 6 e 10h. Alterações semelhantes foram descritas em bovinos (Araújo e Belluomini, 1960-62) e em cães após envenenamento botrópico (Ferreira Jr. e Barraviera, 2004). Provavelmente, a letargia e a apatia nesses animais estejam associadas ao efeito hipotensor do veneno botrópico, devido aos agentes vasodilatadores liberados, como os potenciadores da bradicinina e inibidores da enzima conversora da angiotensina (Picolo et al., 2002). Posteriormente, os animais apresentaram extrema fraqueza entre o quinto e oitavo dias após a inoculação, causada pela diátese hemorrágica instalada local e sistemicamente.

Houve redução no consumo alimentar nos animais do grupo VB, especialmente entre $24 \mathrm{~h}$ até uma semana após. Takahira (1999) também observou anorexia em cães após envenenamento botrópico experimental. Nos animais do grupo VI ocorreu pequena diminuição no consumo alimentar entre 6 e 24h. Como já relatado anteriormente, a rejeição ao alimento pode ter sido provocada pela dor e pelo desconforto. 
Presença de melena foi vista às $54 \mathrm{~h}$ após a inoculação do veneno bruto em três animais, semelhante ao descrito por Santos et al. (2003) em cães, e por Raposo et al. (2000), em um eqüino exposto ao veneno botrópico.

Todos os animais do grupo VB apresentaram hemorragias em feridas recentes e no local inoculado entre 24 e $30 \mathrm{~h}$ após a inoculação, sintomas reportados no envenenamento botrópico em cães (Santos et al., 2003). Da mesma forma, formaram-se hematomas nos sítios de punção venosa entre $24 \mathrm{~h}$ e o oitavo dia e a partir desse tempo observaram-se hematomas em locais de maior traumatismo natural, como o membro posterior e a garupa. A presença de hemorragias locais e distantes do sítio de inoculação do veneno deve-se à presença de metaloproteinases existentes no veneno botrópico, capazes de degradar vasos sangüíneos, além dos efeitos do veneno sobre o sistema hemostático como trombocitopenia e trombopatia (Loría et al., 2003; Yamazaki e Morita, 2004).

Entre 54 e 78h, terceiro e quarto dias, foi verificado TPC acima de cinco segundos nos animais do grupo VB, com retorno à normalidade depois desse tempo, sendo indicativo de hipovolemia conforme Dirksen et al. (1993). Nesse caso o aumento de TPC está relacionado à perda sangüínea associada ao envenenamento botrópico, causada pelas hemorragias generalizadas citadas anteriormente e comprovadas pelo baixo valor médio do hematócrito $(15,5 \%)$.

Nas mucosas dos animais do grupo VB foram vistas hiperemia no período entre 6 e 30h, petéquias entre 10 e $30 \mathrm{~h}$, sufusões associadas à palidez a partir do terceiro dia, que perduraram até o oitavo. Dez dias após o envenenamento botrópico, as mucosas estavam normais, demonstrando a recuperação dos sinais clínicos. Como já relatado anteriormente, essas hemorragias revelam a toxicidade sistêmica do veneno de B. alternatus, causada pela destruição da integridade vascular, trombocitopenia e pelo consumo dos fatores da coagulação (Camey et al., 2002). Todos do grupo VI apresentaram hemorragias petequiais nas mucosas $10 \mathrm{~h}$ após inoculação, vistas até o quarto dia, podendo estar associadas a efeitos residuais das desintegrinas nas plaquetas, semelhante ao resultado verificado por Heneine e Heneine (2001).

Houve aumento do linfonodo cervical superficial direito nos animais do grupo VB a partir das $6 \mathrm{~h}$ até o quinto dia, com retorno à normalidade no $11^{\mathrm{o}}$ dia. Esse aumento é justificado pela inflamação local, característica do envenenamento botrópico. Metaloproteinases, hialuronidases e proteases dispersam o veneno nos tecidos, contribuindo para a absorção das toxinas e provavelmente, a reação do linfonodo foi associada aos efeitos lesivos e antigênicos destas toxinas. Nesse mesmo grupo, oito dias após a inoculação do veneno, ocorreu discreto aumento no linfonodo subilíaco e cervical superficial direito, concomitantemente à assimetria da musculatura regional que perdurou até 25 dias após. Reações em linfonodos não relacionados ao local inoculado com veneno botrópico demonstram a tentativa do organismo em reabsorver hematomas ou degenerações formados nessas regiões, resultantes da desorganização hemostática causada por toxinas como a fração trombina símile e metaloproteinases ou ainda lesões necróticas, devido a proteinases, trombose e isquemia (Camey et al., 2002; Loría et al., 2003).

Nos animais do grupo VI também foi observado aumento no linfonodo cervical superficial direito 10h após inoculação que perdurou até o oitavo dia, demonstrando que as toxinas não foram totalmente modificadas pela iodação.

A freqüência respiratória elevou-se gradativamente e significativamente de 24 tempo zero - para 55 movimentos/minuto até as $54 \mathrm{~h}$ nos animais do grupo VB. Também é importante ressaltar que entre $30 \mathrm{~h}$ até o oitavo dia após, esses valores situaram-se acima dos valores de referência para bovinos (Dirksen et al., 1993), indicando taquipnéia. A partir de 10h e até o $11^{\circ}$ dia após as inoculações dos venenos, no grupo $\mathrm{VB}$, a freqüência respiratória foi mais elevada $(\mathrm{P} \leq 0,05)$ (Tab.1) que no grupo VI. A taquipnéia no envenenamento botrópico também foi relatada em cães (Santos et al., 2003; Silva Jr., 2003) e em bovinos (Menezes, 1995). Possivelmente, a taquipnéia seja decorrente da liberação de adrenalina, devido à dor, e a hiperventilação compensatória à hipotensão, provocadas pelo veneno botrópico. 
Da mesma forma, observou-se taquicardia $(\mathrm{P} \leq 0,05)$ após a inoculação do veneno bruto (Tab. 1), inicialmente causada por dor e posteriormente por um mecanismo compensatório ao choque hipovolêmico apresentado pelos animais. Especialmente entre o quarto e o oitavo dias, os animais apresentaram ritmo em galope e hiperfonese cardíaca, justificados pelo esforço cardíaco compensatório à perda sangüínea aguda e redução na viscosidade do sangue. Até o $11^{\circ}$ dia após a inoculação dos venenos, a freqüência cardíaca foi mais alta $(\mathrm{P} \leq 0,05)$ no grupo $\mathrm{VB}$, exceto às $30 \mathrm{~h}$, e encontra-se acima da referência normal, semelhantemente às descrições realizadas em cães após o envenenamento botrópico (Ferreira Jr. e Barraviera, 2004). Como o grupo que recebeu veneno iodado apresentou freqüência cardíaca similar em todos os momentos (Tab.1), supõe-se que a iodação suprimiu grande parte dos efeitos hemorrágicos deste veneno.

O valor médio da freqüência de pulsação arterial periférica foi menor entre 10 e $54 \mathrm{~h}$ nos animais do grupo VB $(\mathrm{P} \leq 0,05)$ quando comparados com os do grupo VI. Além da bradisfigmia, a pulsação fraca nos bovinos sobreviventes poderia estar relacionada à hipovolemia, liberação de substâncias vasodilatadoras e/ou efeitos diretos no coração, provocados pelo veneno botrópico.

Nos animais do grupo VB, a pulsação arterial periférica não acompanhou a freqüência cardíaca, demonstrando efeitos diferenciados no músculo cardíaco e vasos periféricos, prejudicados pelas metaloproteinases, que degradam a membrana basal (Loría et al., 2003), interferindo na resposta aos estímulos nervosos, além dos efeitos de hipovolemia e hipotensão.

Apesar de os animais do grupo VB apresentarem temperatura retal mais alta $(\mathrm{P} \leq 0,05)$ entre $\mathrm{O}$ segundo e quinto dias quando comparados com os do grupo VI, percebe-se que todos os animais independentemente do tipo de veneno recebido sofrem os mesmos efeitos.

A freqüência dos movimentos ruminais não se alterou entre os tempos dentro de cada grupo. Porém, quando se compararam os grupos, nos animais do grupo VB a freqüência foi menor às $6 \mathrm{~h}$ e no terceiro e quinto dias. Esses resultados podem ser decorrentes de dor, estresse e menor consumo alimentar.

Apesar de os animais de ambos os grupos apresentarem aumento de circunferência do membro no qual foi inoculado veneno, os do grupo VB apresentaram maiores valores médios, especialmente entre 6 e 10h, quando comparados com os do grupo VI (Tab. 1). O edema era firme e quente e regrediu totalmente no $25^{\circ}$ dia. Já no grupo VI, somente um animal apresentou grande edema às $10 \mathrm{~h}$ e nos demais, este foi de média magnitude. Nesse grupo, a presença de edema pode ser atribuída à ação irritante do iodo utilizado para a iodação ou às toxinas não detoxificadas, conforme descrito por Heneine e Heneine (2001).

O edema é um sinal característico nos animais envenenados por serpentes do gênero Bothrops descrito em humanos e em várias espécies animais como cães (Silva Jr., 2003), camundongos (Barbosa et al., 2003), coelhos (Melo et al., 2005) e é decorrente da intensa reação inflamatória.

Em um bovino do grupo VB foi vista ulceração dérmica $(4 \times 2 \mathrm{~mm})$ no local de inoculação do veneno $30 \mathrm{~h}$ após até o oitavo dia. A necrose e suas seqüelas são bem relatadas no envenenamento botrópico (Santos et al., 2003; Melo et al., 2005). Nesse grupo, a espessura média da dobra de pele foi maior entre os tempos e quando comparada a dos animais do grupo VI $(\mathrm{P} \leq 0,05)$ entre $6 \mathrm{~h}$ e o quinto dia. Nesse grupo, a espessura da dobra de pele aumentou $(\mathrm{P} \leq 0,05)$ entre $10 \mathrm{~h}$ e o terceiro dia, indicando menor duração e regressão mais rápida do edema.

No teste de Western Blotting, aos 17 e 24 dias, verificou-se ausência de reação no soro negativo, reação positiva nos três animais sobreviventes que receberam veneno bruto de B. alternatus e ausência de reação nos cinco que receberam veneno botrópico iodado. Essa ausência de reação pode representar a perda ou alteração de epitopos conformacionais, provavelmente causada pela inativação por adição da solução de iodo. Os animais podem ter desenvolvido anticorpos antiveneno iodado ou não terem desenvolvido anticorpos.

Aos 31 e 45 dias verificou-se ausência de reação no soro negativo e em todos os animais do grupo 
VI, e reação positiva num único animal sobrevivente que recebeu veneno bruto de $B$. alternatus. Theakston et al. (1981a,b) e Barraviera et al. (1996) detectaram a presença de anticorpos em pessoas picadas por serpentes por até três meses. Jácome (2002), ao estudar a cinética do veneno de Bothrops alternatus após a inoculação experimental em cães e a produção de anticorpos séricos, relatou a presença de $\mathrm{IgG}$ até 35 dias após.

Aos 60 e 180 dias, verificou-se ausência de reação no soro negativo em todos os animais do grupo VI e nos três animais sobreviventes que receberam veneno bruto de $B$. alternatus. Estes resultados indicam que venenos de serpentes são imunógenos fracos, conforme descrito por Spencer (1996) e que, as melhores respostas imunes são desencadeadas pelo veneno bruto (Sriprapat et al., 2003). Portanto, a iodação não foi um método eficaz, pois deveria ter suprimido apenas a toxicidade e não a imunogenicidade.

\section{CONCLUSÕES}

Em uma mesma concentração testada, o veneno bruto causou graves alterações clínicas, óbitos e produção de anticorpos circulantes nos bovinos sobreviventes enquanto o veneno iodado foi capaz de suprimir a letalidade dos animais mas não apresentou resposta imunológica satisfatória.

\section{AGRADECIMENTOS}

Prof. Dr. Paulo Roberto Cecon e Profa. Dra. Ângela Maria Quintão Lana, pelas consultorias estatísticas.

\section{REFERÊNCIAS BIBLIOGRÁFICAS}

ARAÚJO, P.; BELLUOMINI, E. Toxicidade de venenos ofídicos. I - Sensibilidade específica de animais domésticos e de laboratório. Mem. Inst. Butantan, v.30, p.133-142, 1960-62.

ARAÚJO, P.; ROSENFELD, G.; BELLUOMINI, W. Toxicidade de venenos ofídicos. II- Doses mortais para bovinos. Arq. Inst. Biol., v.30, p.43-48, 1963.

BARBOSA, A.M.; AMARAL, R.O.; TEIXEIRA, C.F.P. et al. Pharmacological characterization of mouse hind paw oedema induced by Bothrops insularis (Jararaca ilhoa) snake venom. Toxicon, v.42, p.515-523, 2003.
BARRAVIERA, B.; SARTORI, A.; SILVA, M.F.P. et al. Use of an ELISA assay to evaluate venom, antivenom, IgG and IgM human antibody levels in serum and cerebrospinal fluid from patients bitten by Crotalus durissus terrificus in Brazil. J. Venom. Anim. Toxins, v.2, p.14-27, 1996.

BAUAB, F.A.; JUNQUEIRA, G.R.; MORATOCORRADINI, M.C. et al. Clinical and epidemiological aspects of the 'urutu' lance-headed viper (Bothrops alternatus) bite in Brazilian hospital. Trop. Med. Parasitol., v.45, p.243-245, 1994.

BIONDO, A.W.; BICUDO, P.L.; KOHAYAGAWA, A. Acidentes ofídicos em medicina veterinária: revisão de 1260 notificações do Instituto Butantan. In: JORNADA CIENTÍFICA DA ASSOCIAÇÃO DE DOCENTES, 28., Botucatu, 1993. Anais... Botucatu: UNESP, 1993, p.159 (Resumo).

CAMEY, K.U.; VELARDE, D.T.; SANCHEZ, E.F. Pharmacological characterization and neutralization of venoms used the production of Bothropic antivenom in Brazil. Toxicon, v.40, p.501-509, 2002.

DANIEL, J.P.; HENEINE, L.G.D.; TAVARES, C.A.P. et al. Generation of protective immune sera by Crotalus durissus terrificus venom detoxified by controlled iodation. Braz. J. Med. Biol. Res., v.20, p.713-720, 1987.

DIRKSEN, G.; GRÜNDER, H.-D.; STÖBER, M. et al. (Eds.). Exame clínico dos bovinos. 3.ed. Rio de Janeiro: Guanabara Koogan, 1993. 419p.

FERREIRA Jr., R.S.; BARRAVIERA, B. Management of venomous snakebites in dogs and cats in Brazil. J. Venom. Toxins Incl. Trop. Dis., v.10, p.112-132, 2004.

HENEINE, L.G.D. Destoxificação por iodação controlada da fração T2 e veneno total do escorpião Tytyus serrulatus e estudo imunológico dos derivados. 1986. 59f. Dissertação (Mestrado) - Instituto de Ciências Biológicas, Universidade Federal de Minas Gerais, Belo Horizonte.

HENEINE, L.G.D.; HENEINE, I. Modifications of biological properties of protein toxins by stepwise iodination. J. Toxicol. Toxin. Rev., v.20, p.209-228, 2001.

JÁCOME, D.O. Avaliação da produção de imunoglobulinas e distribuição sérica do veneno de Bothrops alternatus em cães experimentalmente envenenados e submetidos a diferentes tratamentos. 2002. 64f. Dissertação (Mestrado) - Escola de Veterinária, Universidade Federal de Minas Gerais, Belo Horizonte.

LORÍA, G. D.; RUCAVADO, A.; KAMIGUTI, A.S. et al. Characterization of 'basparin A', a prothrombinactivating metalloproteinase, from the venom of the snake Bothrops asper that inhibits platelet aggregation 
and induces defibrination and thrombosis. Arch. Biochem. Biophys., v.418, p.13-24, 2003.

MELO, M.M.; HABERMEHL, G.G.; OLIVEIRA, N.J.F. et al. Treatment of Bothrops alternatus envenomation by Curcuma longa and Calendula officinalis extracts and ar-turmerone. Arq. Bras. Med. Vet. Zootec., v. 57, p.7-17, 2005.

MENEZES, R.V. Ofidismo em bovinos. Arq. Esc. Med. Vet. UFBA, v.18, p.224-231, 1995.

PICOLO, G.; CHACUR, M.; GUTIÉRREZ, J.M. et al. Evaluation of antivenoms in the neutralization of hyperalgesia and edema induced by Bothrops jararaca and Bothrops asper snake venoms. Braz. J. Med. Biol. Res., v.10, p.1221-1228, 2002.

RAPOSO, J.B.; MÉNDEZ, M.C.; BAIALARDI, C.E.G. et al. Acidente ofídico em eqüino no sul do Brasil - Relato de caso. Rev. Fac. Zootec. Vet. Agr., v.7, p.5-8, 2000

SANTOS, M.M.B.; MELO, M.M.; JACOME, D.O. et al. Avaliação clínica de cães tratados com flunixina meglumina, Curcuma longa e soro antibotrópico após envenenamento botrópico experimental (Bothrops alternatus). Acta Sci. Vet., v.31, p.31-38, 2003.

SILVA Jr., P.G.P. Avaliação clínica e laboratorial de cães tratados com extrato de Kalanchoe brasiliensis $e$ soro antibotrópico após o envenenamento botrópico experimental (Bothrops alternatus Duméril, 1854). 2003. 133f. Dissertação (Mestrado) - Escola de Veterinária, Universidade Federal de Minas Gerais, Belo Horizonte.

SISTEMA de análises estatísticas e genéticas. Versão 8.0 - SAEG. Viçosa: UFV, 1998
SOERENSEN, B.; BARROS, A.R.; ZEZZA NETO, L. et al. Aspecto clínico e laboratorial do envenenamento botrópico e crotálico em bovinos. Unimar Cien., v.4, p.28-33, 1995.

SPENCER, P.J. Biochemical and immunological alterations of ${ }^{60} \mathrm{Co}$ irradiated Bothrops jararacussu venom. J. Venom. Anim. Toxins, v.2, p.165, 1996.

SRIPRAPAT, S.; AEKSOWAN, S.; SAPSUTTHIPAS, $\mathrm{S}$. et al. The impact $\mathrm{f}$ a low dose, low volume, multi-site immunization on the production the therapeutic antivenoms in Thailand. Toxicon, v.41, p.57-64, 2003.

TAKAHIRA, R.K. Perfil hematológico, hemostático, bioquímico e histopatológico do envenenamento experimental de cães por Bothrops alternatus (Duméril, 1854) e Bothrops moojeni (Hoge, 1966). 1999. 195f. Tese (Doutorado) - Faculdade de Medicina Veterinária e Zootecnia, Universidade Estadual Paulista, Botucatu, SP.

THEAKSTON, R.D.G.; PUGH, R.N.H.; REID, H.A. Enzyme-linked immunosorbent assay of venomantibodies in human victims of snake bite. J. Trop. Med. Hyg., v.84, p.109-112, 1981a.

THEAKSTON, R.D.G.; REID, H.A.; LARRICK, J.W. Snake venom antibodies in Ecuadorian indians. $J$. Trop. Med. Hyg., v.84, p.199-202, 1981 b.

YAMAZAKI, Y.; MORITA, T. Strucuture and function of snake venom cysteine-rich secretory proteins. Toxicon, v.44, p.227-231, 2004.

WORLD HEALTH ORGANIZATION. Bites and stings due to terrestrial and aquatic animals in Europe. Weekly Epidemiol. Rec., v.76, p.290-300, 2001. 